\title{
CARACTERIZAÇÃO MINERALÓGICA E BENEFICIAMENTO DO CAULIM DE PRADO (BA)
}

\author{
L. C. Bertolino ${ }^{1}$, M. L. Torem ${ }^{2}$, R. B. Scorzelli ${ }^{3}$ e A. M. Rossi ${ }^{3}$ \\ ${ }^{1}$ Centro de Tecnologia Mineral - MCTI. ${ }^{2}$ Departamento de Engenharia de Materiais - PUC ${ }^{3}$ Centro \\ Brasileiro de Pesquisas Físicas - MCTI e-mail: Icbertolino@cetem.gov.br
}

Artigo submetido em outubro/2012 e aceito em agosto/2012

\section{RESUMO}

Na região de Prado, sul da Bahia, Brasil, ocorre um importante depósito de caulim que tem sido explotado pela Mineração de Caulim Monte Pascoal desde 1992. O caulim destina-se principalmente à indústria do papel e para produção de catalisadores utilizados no craqueamaneto do petróleo. O depósito apresenta dois tipos distintos de minério. $\mathrm{O}$ caulim da base da sequência é de origem primária, qualidade superior e destina-se principalmente à indústria do papel. O caulim do topo é de origem sedimentar e de qualidade inferior, baixo grau de cristalinidade e alto teor de ferro e destina-se principalmente à indústria de catalisadores.

O caulim foi submetido ao processo separação magnética e tratamento com agente redutor, ditionito de sódio, visando elevar o índice de alvura e eliminar as impurezas mineralógicas presentes no caulim. As amostras foram caracterizadas através da difratometria de raios $X$, microscopia eletrônica de varredura e ressonância paramagnética eletrônica-RPE. Os espectros de RPE das amostras de caulim exibem ressonâncias paramagnéticas ( $\mathrm{g}=4,9$ e 4,2) atribuídas ao $\mathrm{Fe}^{3+}$ em sítios de simetria octaedral na estrutura da caulinita substituindo o $\mathrm{Al}^{3+}$ e ressonância ferromagnéticas $(\mathrm{g}=$ $2,0)$ associadas a óxidos e/ou hidróxidos de ferro presentes em fases externas a caulinita.

PALAVRAS-CHAVE: caulim, beneficiamento, caracterização mineralógica.

MINERALOGICAL CHARACTERIZATION AND BENEFICIATION OF KAOLIN FROM PRADO (BA)

\section{ABSTRACT}

In the region of Prado southern Bahia State, Brazil, there are large deposits of kaolin. The ore has been mined by Mineração de Caulim Monte Pascoal Company, since 1992 and it has been mainly used in the paper industry and the production of catalyzers for petroleum industry. The mineral deposit has two very distinct levels. The kaolin of base sequence is of superior quality and is used primarily in the paper industry. The kaolin at the top of sequence it is of sedimentary origin, color ranging from light gray to light brown, low degree of crystallinity and high iron content. The kaolin was submitted to processes used in industry treatment with a redutor agent, sodium dithionite, and magnetic separation to increase the brightness and eliminating mineralogical impurities from the kaolin. The sample mineralogical and structural characteristics were determined by X-ray diffraction, scanning electron microscopy (SEM) and electron spin resonance (ESR). The Electron Spin Resonance (ESR) spectrums of kaolin samples shown paramagnetic resonance ( $\mathrm{g}=4.9$ and 4.2 ), attributed to iron in sites of octahedral symmetry in the kaolinite replacing $\mathrm{Al}^{3+}$ and ferromagnetic resonance $(\mathrm{g}=2.0$ ) associated with iron in external phases of the kaolinite (oxides and/or iron hydroxides).

KEY-WORDS: kaolinite, beneficiation, mineralogical characterization 


\section{CARACTERIZAÇÃO MINERALÓGICA E BENEFICIAMENTO DO CAULIM DE PRADO (BA)}

\section{INTRODUÇÃo}

O caulim é um mineral industrial importante nos vários mercados mundiais incluindo aplicações em cobertura e carga de papel, cerâmica, tintas, plásticos, borracha, fibras de vidro, suporte de catalisadores de craqueamento de petróleo e muitas outras utilizações. Os minerais que constituem o caulim, caulinita, haloisita, dickita e nacrita, possuem composição química essencialmente similar, porém, cada um deles tem diferenças estruturais importantes. O mineral de caulim mais comum e mais importante, industrialmente, é a caulinita $\left[\mathrm{Al}_{2} \mathrm{Si}_{2} \mathrm{O}_{5}(\mathrm{OH})_{4}\right](\mathrm{Grim}, 1968)$. A caulinita pode ser formada como um produto do intemperismo residual, por alteração hidrotermal, e como um mineral sedimentar autigênico. As ocorrências residuais e hidrotermais são classificadas como primárias e as ocorrências sedimentares como secundárias (Murray e Keller, 1993).

O caulim ocorre associado a diversas impurezas, sendo necessários processos de beneficiamento eficientes para adequá-lo ao uso industrial (Singh et al., 1991; Luz et al., 2008, Prasad et al., 1991).

A classificação granulométrica é a principal etapa do beneficiamento, onde a polpa do minério é submetida, inicialmente, a várias etapas de classificação através de peneiras e hidrociclones. Esta etapa visa basicamente eliminar as impurezas mineralógicas com tamanho de partícula maior do que $74 \mu \mathrm{m}$, no caso do produto destinar-se ao mercado de carga de papel, tinta, plástico etc. Quando se deseja obter um produto para cobertura de papel, na sequência da classificação, vem o fracionamento em centrífugas tipo Bowl, obtendo-se produtos com granulometria acima de $80 \%<2 \mu \mathrm{m}$ (Monte et al., 2001)

A separação magnética criogênica, em campo de alta intensidade, é uma operação normalmente utilizada pelas empresas produtoras de caulim destinado à indústria de papel do tipo coating. A operação consiste em submeter a polpa de caulim a um campo magnético de alta intensidade (50.000 Gauss), onde grande parte dos óxidos e hidróxidos de ferro associados ao caulim e ilmenita ou rutilo com ferro na estrutura cristalina ficam retidos na lã de aço do separador.

A operação de lixiviação redutora (alvejamento químico) com ditionito de sódio $\left(\mathrm{Na}_{2} \mathrm{~S}_{2} \mathrm{O}_{4}\right)$ visa reduzir o teor de ferro presente no minério através da redução do $\mathrm{Fe}^{3+}$, insolúvel, à $\mathrm{Fe}^{2+}$, solúvel (Bertolino et al., 2010). O tratamento com ditionito de sódio é um processo de alvejamento usado na maioria das empresas produtoras de caulim (Scorzelli et al., 2008).

Uma importante jazida de caulim localizada na região de Prado, Bahia, tem se destacado no mercado interno pela qualidade do seu minério e pela proximidade do mercado consumidor. $\mathrm{O}$ depósito apresenta dois tipos de minérios bem distintos: primário e secundário. $\mathrm{O}$ caulim da base é de qualidade superior e destina-se à indústria do papel, já o do topo da sequência apresenta menor índice de alvura sendo utilizado principalmente na produção de catalisadores. 
O estudo teve como objetivo a caracterização mineralógica e tecnológica do caulim de Prado, visando a sua aplicação industrial.

\section{MATERIAIS E MÉTODOS}

Foram estudadas oito (08) amostras de caulim provenientes de duas jazidas (Minas Caliman e Walmor) pertencentes à Mineração de Caulim Monte Pascoal Ltda., localizadas no município de Prado, sul do estado da Bahia, coordenadas geográficas $17^{\circ} 20^{\prime} 28^{\prime \prime} \mathrm{S}$ e $39^{\circ} 13^{\prime} 15^{\prime \prime} \mathrm{O}$. As amostras (run of mine) foram coletadas na frente de lavra e após o processo de beneficiamento (coating e extrafino) da empresa (Tabela 1 ).

As amostras foram submetidas à secagem, homogeneização e quarteamento, classificação granulométrica, separação magnética, alvejamento químico e determinação de alvura. As amostras foram secas ao sol por aproximadamente seis horas, e, posteriormente, homogeneizadas em pilhas cônicas e longitudinais. A classificação granulométrica foi realizada utilizando as peneiras 74, 53 e $44 \mu \mathrm{m}$. A fração < $44 \mu \mathrm{m}$ foi submetida à separação magnética no separador Boxmag Rapid, em campo de 15.000 Gauss. A fração não magnética foi submetida ao alvejamento químico com ditionito de sódio.

No alvejamento químico, utilizou-se uma polpa com $30 \%$ de sólido, com pH mantido entre e 3,0 e 3,5 através da adição de $\mathrm{H}_{2} \mathrm{SO}_{4}$. Em seguida adicionou-se ditionito de sódio $\left(\mathrm{Na}_{2} \mathrm{~S}_{2} \mathrm{O}_{4}\right)$ na concentração de $4 \mathrm{~kg} / \mathrm{t}$, por um período de 2 horas.

Tabela 1. Identificação das amostras

\begin{tabular}{|l|l|l|}
\hline \multicolumn{2}{|c|}{ Localização } & \multicolumn{1}{c|}{ Amostra } \\
\hline \multirow{3}{*}{ Mina Caliman } & \multirow{3}{*}{ Unidade Inferior } & MPC01 \\
\cline { 3 - 3 } & & MPC02 \\
\cline { 2 - 3 } & \multirow{3}{*}{ Unidade Superior } & MPCoating \\
\cline { 3 - 3 } & & MPC03 \\
\cline { 3 - 3 } & & MPC04 \\
\hline Mina Walmoxtrafino & MPW01 \\
\cline { 3 - 3 } & & MPW02 \\
\hline
\end{tabular}

As amostras de caulim foram caracterizadas através de lupa binocular, microscópio eletrônico de varredura/EDS, difratometria de raios $X$ (DRX), análises químicas e ressonância paramagnética eletrônica (RPE).

As análises de RPE foram realizadas em amostras de caulim submetidas a diferentes fases do tratamento para estimar e acompanhar a influência do processo de retirada do ferro (Meads e Malden, 1975; Balan et al., 2000; Lombardi et al., 2002), na alvura do caulim. Estes estudos foram complementados com a análise química das amostras, principalmente no que diz respeito ao conteúdo de ferro total, $\mathrm{Fe}^{2+}$ e $\mathrm{Fe}^{3+}$ e por difratometria de raios $\mathrm{X}$. 


\section{DEPÓSITOS DE CAULIM DA REGIÃO DE PRADO}

Os depósitos de caulim do sul da Bahia pertencem a unidade geológica denominada de Grupo Barreiras (Bigarella, 1975), formada por depósitos de sedimentos terrígenos dispersos na forma de tabuleiros em patamares ligeiramente inclinados para o litoral. Os sedimentos são constituídos por camadas de espessura variada de sedimentos arenosos de coloração bege ou levemente esbranquiçado, ricos em caulinita e quartzo.

Na mina Caliman ocorrem dois tipos de depósitos de caulim bem distintos, no topo da sequência ocorre uma espessa camada de caulim associado à Formação Barreiras, de origem secundária (Unidade Superior). Na base ocorre um segundo tipo de caulim de coloração mais clara e de granulometria mais grossa, facilmente diferenciado dos demais caulins da região (Unidade Inferior - Primário) (Bertolino, 2000).

O Caulim da Unidade Inferior tem a sua ocorrência restrita à porção inferior da mina Caliman, a aproximadamente 25 metros de profundidade. O caulim dessa unidade diferencia-se do topo da sequência pela sua coloração mais clara, granulometria mais grossa e ausência de estruturas sedimentares. Devido às características físicas e mineralógicas, o caulim da base é de qualidade superior, sendo destinado principalmente à indústria do papel, comercialmente é denominado como do tipo coating.

Em afloramento, o minério apresenta-se muito homogêneo, tanto lateralmente quanto verticalmente. O minério é constituído principalmente por caulinita, quartzo, muscovita; secundariamente ocorrem granada, zircão e turmalina.

A transição do caulim da base para a Unidade Superior é facilmente observada na região central da mina Caliman, sendo marcada pela presença de uma linha contínua de seixos de quartzo (stone line) e pela diferença na coloração do caulim.

O Caulim da Unidade Superior ocorre na porção superior das minas Caliman e Walmor. Esses depósitos de caulim são de origem sedimentar, de idade terciária e estão associados ao Grupo Barreiras (Bigarella, 1975). O caulim é de granulometria fina, coloração levemente avermelhada a bege claro, baixo grau de cristalinidade e apresenta alto teor de ferro, sendo comum a presença de concreções ferruginosas.

Em afloramento, principalmente na mina Caliman, são observadas estruturas sedimentares de pequeno porte e variações granulométricas ao longo do perfil. As variações são associadas às condições geológicas de formação dos depósitos. Os minerais zircão, ilmenita e a monazita ocorrem associados ao caulim, não ultrapassando $1 \%$ do total do minério; estes ocorrem preferencialmente na fração granulométrica maior que $44 \mu \mathrm{m}$. 


\section{RESULTADOS}

Através dos difratogramas de raios $\mathrm{X}$ observa-se que após as etapas de beneficiamento, as amostras são constituídas essencialmente por caulinita. Na Figura 1 observa-se que as amostras analisadas apresentam variações na intensidade e na largura dos picos 001 (7,149 ̊) e $002(3,572 \AA$ A $)$ da caulinita. Os picos 001 e 002 das amostras MPC01 e MPC02 são mais intensos e com uma menor largura a meia altura, que nas amostras MPC03 e MPC04. Este comportamento está associado o índice de alvura.

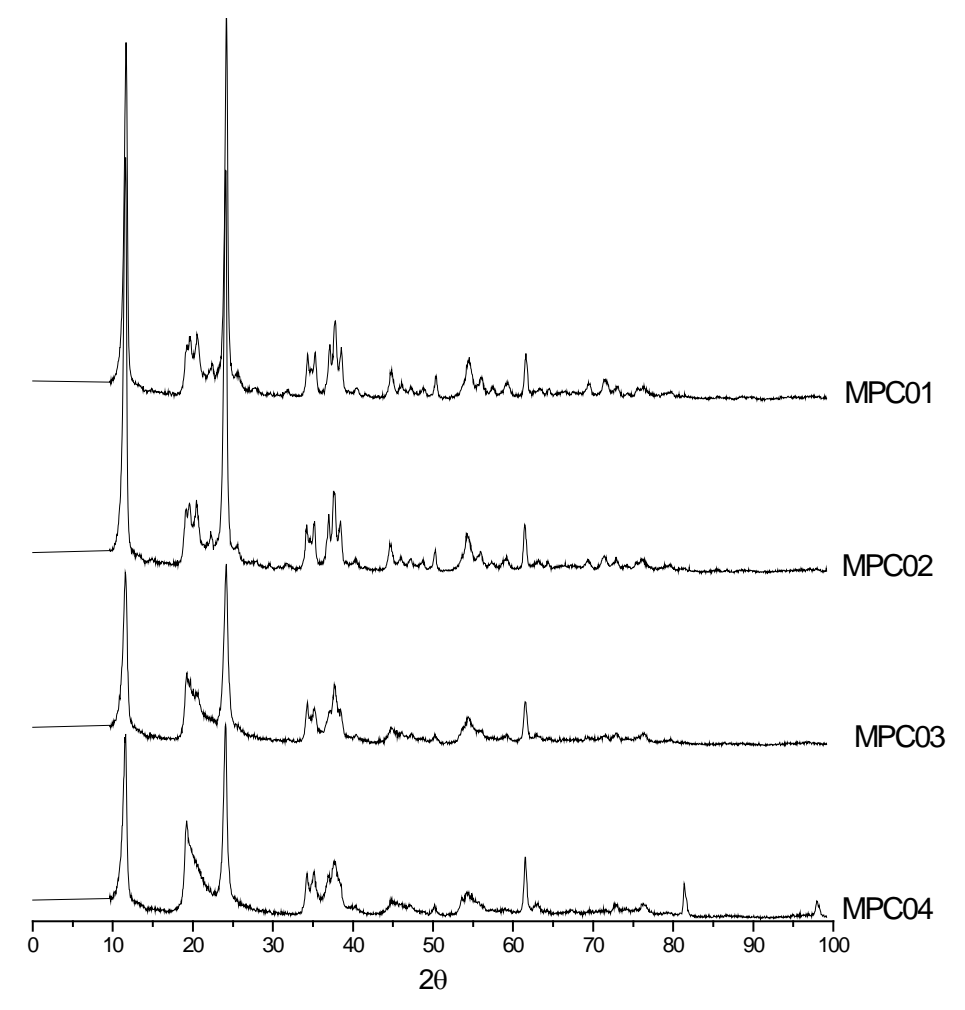

Figura 1. Difratogramas de raios $X$ das amostras MPC01, 02, 03 e 04 . CuKa (40 kV/40 mA).

O caulim da região de Prado apresenta grande variação na granulometria, corroborando os dados observados em campo. O caulim da Unidade Inferior (MPC01 e MPC02) tem granulometria mais grossa e distribuição mais heterogênea, enquanto o caulim da Unidade Superior (MPCO3 e MPC04) possui granulometria fina (Figura 2). 


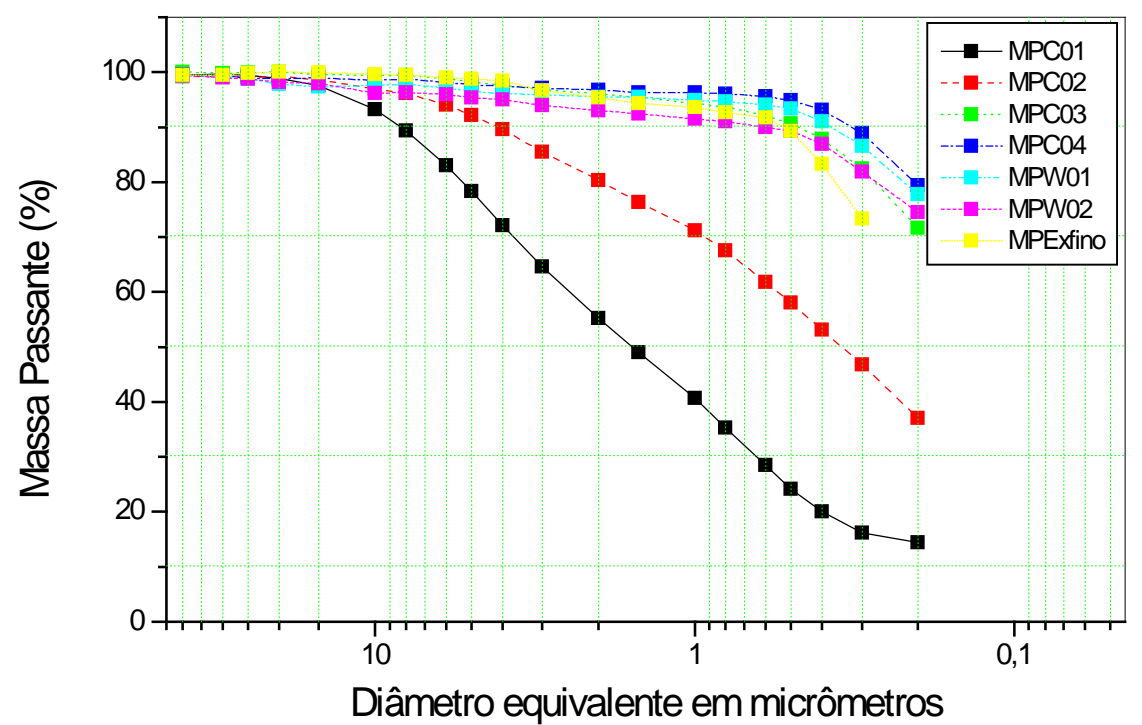

Figura 2. Distribuição granulométrica do caulim das minas Calimam (MPC01, 02, 03 e 04) e Walmor (MPW01 e 02) e do caulim beneficiado (Extrafino)

Nas Figuras 3 e 4 representam as imagens obtidas por microscopia eletrônica de varredura das amostras MPCO1 e MPCO4, complementando as análises da difratometria de raios X. Em ambas as amostras, observam-se que os grãos de caulinita ocorrem na forma de pseudohexágonos empilhados, em uma estrutura denominada booklet. As principais impurezas observadas foram o quartzo e micas.
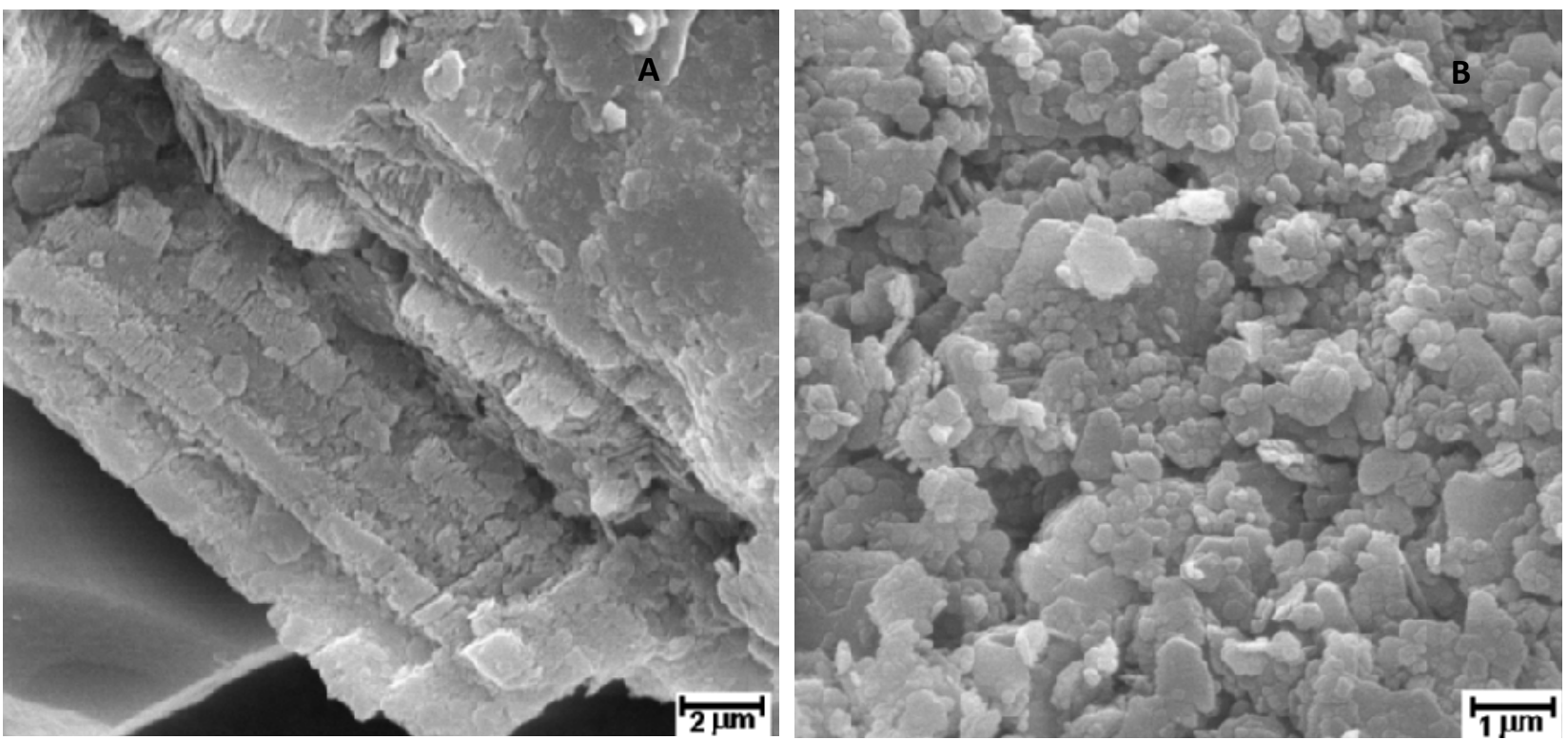

Figura 3. Imagens do caulim MPC01. A- antes do beneficiamento; B- após o beneficiamento. MEV - Elétrons secundários. 


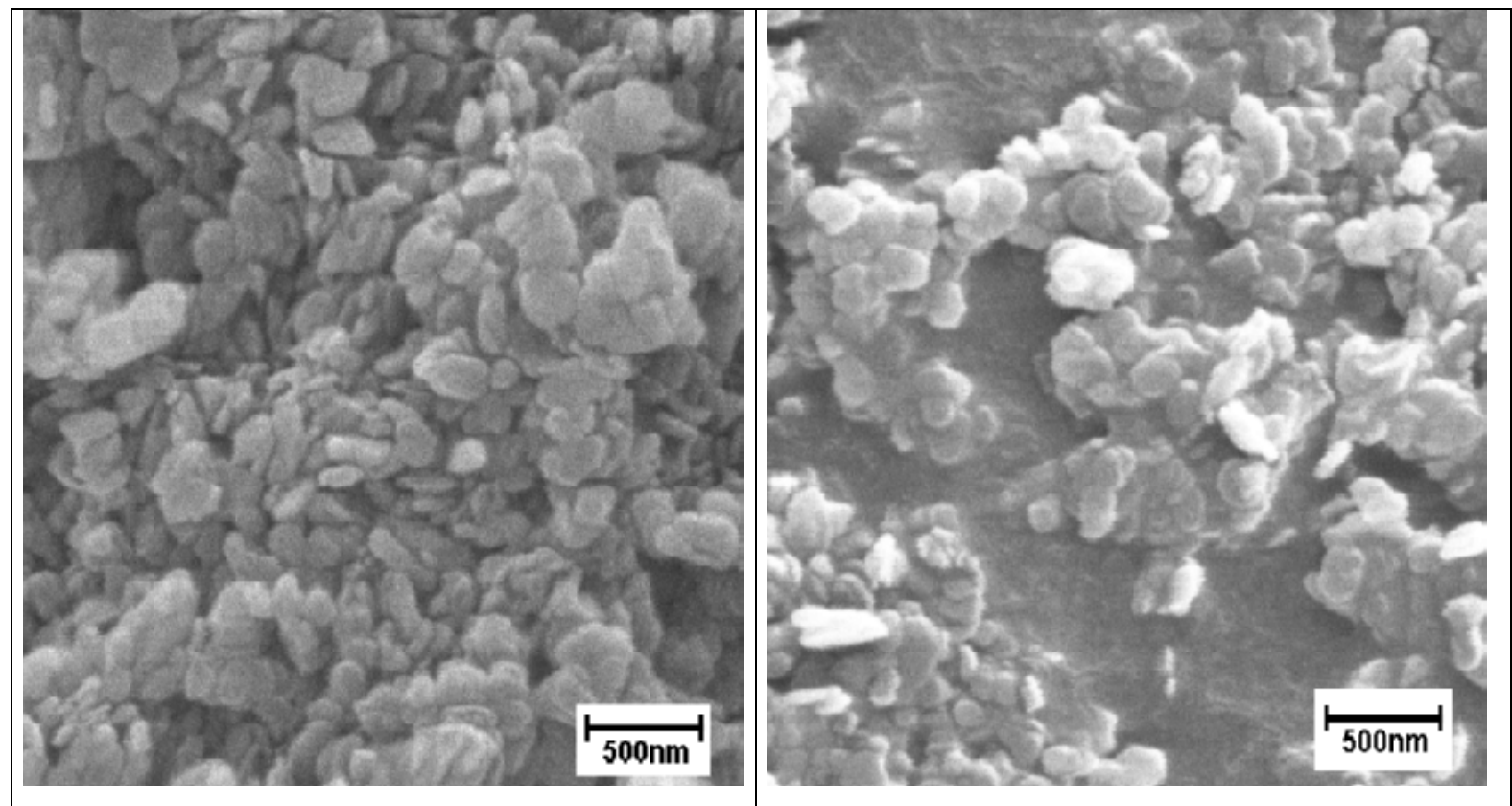

Figura 4. Imagens do caulim da amostra MPC04. MEV - Elétrons secundários.

Os resultados das análises químicas das amostras de caulim são apresentados na Tabela 2. Os teores de $\mathrm{SiO}_{2}$ variam de 41,2 a $45,5 \%$ e o $\mathrm{Al}_{2} \mathrm{O}_{3}$ de 35,2 a $39,1 \%$. Com exceção da amostra MPW01 (1,05), as demais apresentaram estequiometria $\mathrm{SiO}_{2} / \mathrm{Al}_{2} \mathrm{O}_{3}$ em torno de 1,20.

O conteúdo de ferro total varia de 1,55 a 3,04\%, sendo que o $\mathrm{Fe}_{2} \mathrm{O}_{3}$ é mais abundante do que o FeO. O teor relativamente alto de $\mathrm{TiO}_{2}$ nas amostras MPC02 (1,8\%), MPW01 (1,1\%) e MPExtrafino $(1,1 \%)$ deve estar associado à presença de ilmenita.

Tabela 2. Análises químicas das amostras de caulins (\% em peso)

\begin{tabular}{|l|l|l|l|l|l|l|l|l|l|l|l|}
\hline Amostra & $\mathrm{SiO}_{2}$ & $\mathrm{Al}_{2} \mathrm{O}_{3}$ & $\mathrm{CaO}$ & $\mathrm{Fe}_{2} \mathrm{O}_{3}$ & $\mathrm{FeO}$ & $\begin{array}{c}\mathrm{Fe} \\
\text { total }\end{array}$ & $\mathrm{TiO}_{2}$ & $\mathrm{MnO}$ & $\mathrm{MgO}$ & P.F. & Total \\
\hline MPC01 & 45,4 & 37,8 & 0,01 & 1,3 & 0,25 & 1,55 & 0,49 & $<0,01$ & $<0,10$ & 13,85 & 99,10 \\
\hline MPC02 & 44,1 & 35,2 & $<0,01$ & 3,3 & 0,14 & 3,44 & 1,8 & $<0,01$ & $<0,10$ & 13,74 & 98,28 \\
\hline MPC03 & 44,5 & 36,0 & $<0,01$ & 2,9 & 0,14 & 3,04 & 0,94 & $<0,01$ & $<0,10$ & 14,05 & 98,53 \\
\hline MPC04 & 44,0 & 37,8 & 0,01 & 1,6 & 0,18 & 1,78 & 0,98 & $<0,01$ & $<0,10$ & 14,40 & 98,97 \\
\hline MPW01 & 41,2 & 39,1 & 0,01 & 1,4 & 0,21 & 1,61 & 1,1 & $<0,01$ & $<0,10$ & 15,87 & 98,89 \\
\hline MPExfino & 43,7 & 37,4 & 0,01 & 1,6 & 0,18 & 1,78 & 1,1 & $<0,01$ & $<0,10$ & 14,75 & 98,74 \\
\hline MPCoat & 45,0 & 36,9 & 0,03 & 2,1 & 0,32 & 2,42 & 0,90 & 0,02 & $<0,10$ & 13,99 & 99,26 \\
\hline
\end{tabular}

P.F. - Perda ao fogo 
Na Tabela 3 são apresentados os valores do índice de alvura das amostras após as etapas de beneficiamento físico e alvejamento com ditionito de sódio, a amostra MPC02 atingiu maior índice de alvura ( $87,2 \%$ ISO) e a amostra MPW01 menor índice $(69,5 \%$ ISO)

Tabela 3. Índice de alvura do caulim (\% ISO) após beneficiamento

\begin{tabular}{|l|c|}
\hline \multicolumn{1}{|c|}{ Amostra } & $\begin{array}{c}\text { Alvura } \\
\text { \% ISO }\end{array}$ \\
\hline MPC01 & 86,8 \\
\hline MPC02 & 87,2 \\
\hline MPCoating & 82,5 \\
\hline MPC03 & 80,6 \\
\hline MPC04 & 81,0 \\
\hline MPExtrafino & 70,1 \\
\hline MPW01 & 69,5 \\
\hline MPW02 & 70,3 \\
\hline
\end{tabular}

Devido à complexidade da estrutura da caulinita, procurou-se caracterizar os diversos ambientes do ferro através da ressonância paramagnética eletrônica (RPE). Os espectros de RPE mostram que parte do $\mathrm{Fe}^{3+}$ encontra-se substituindo $0 \mathrm{Al}^{3+}$ em sítios octaedrais na estrutura da caulinita ( $g=4,9$ e 4,2 ), e parte encontra-se externo à estrutura do mineral. As evidências indicam que o ferro responsável pela banda larga na região do $g=2$ está adsorvido a superfície da caulinita, provavelmente entre as diversas lamelas que constituem o mineral.

Os óxidos ferro adsorvidos entre as lamelas da caulinita provavelmente são os responsáveis pela diminuição do índice de alvura do caulim. Apesar desse ferro encontrar-se externamente à estrutura do mineral, ele não é facilmente removido durante a separação magnética e lixiviação química com ditionito de sódio.

Na Figura 5 são apresentados espectros de RPE das amostras de caulim. Os espectros das amostras podem ser individualizados em dois grupos com características bem distintas. As amostras da MPC01 e MPC02 apresentam sinais menos intensos na região do $g=4,2$ e dois sítios de ocupação do ferro. No entanto, os sinais das amostras da MPC03 e MPCO4 são mais intensos. 


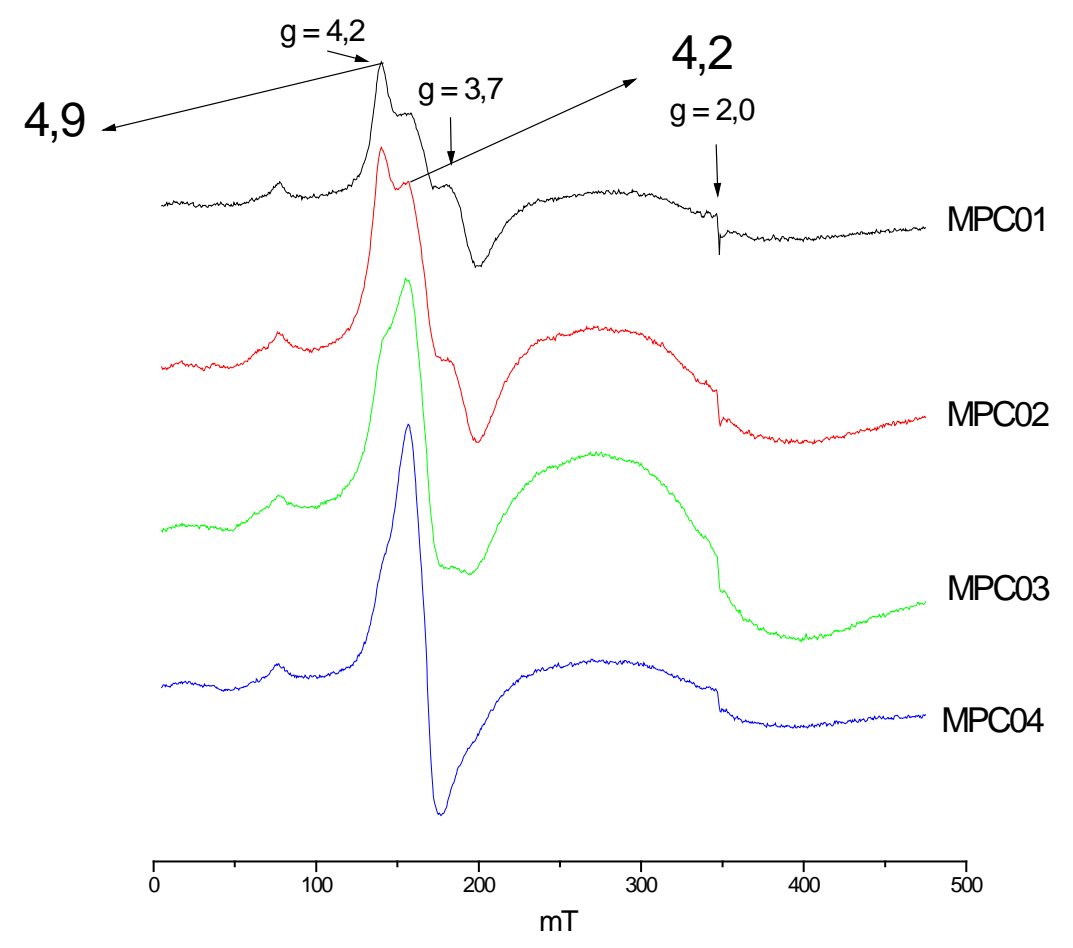

Figura 5. Espectros de ressonância paramagnética eletrônica das amostras MPC01, 02, 03 e 04.

\section{CONCLUSÕES}

Os depósitos de caulim da região de Prado são constituídos por duas sequências distintas. O caulim da base é de granulometria grossa e apresenta alvura superior e maior índice de cristalinidade. $\mathrm{O}$ caulim do topo da sequência é de origem secundária, de coloração cinza claro a creme claro, baixo grau de cristalinidade e maior teor de ferro.

O beneficiamento físico e a lixiviação redutora com ditionito de sódio promovem aumento da alvura do minério, no entanto, observou-se que o tratamento não é capaz de eliminar todo o ferro presente no caulim.

A ressonância paramagnética eletrônica mostrou-se uma técnica extremamente importante na determinação da distribuição do $\mathrm{Fe}^{3+}$ nas amostras de caulim. Os espectros de RPE exibem ressonância paramagnética ( $g=4,9$ e 4,2) atribuídas ao ferro em sítios de simetria octaedral na estrutura da caulinita substituindo o $\mathrm{Al}^{3+}$ e ressonância ferromagnéticas $(\mathrm{g}=2,0)$ associadas a óxidos de ferro presentes em fases externas à caulinita.

O ferro sensível à separação magnética é associado às frações de óxidos superficiais. O ferro estrutural e o ferro encontrado na forma de pequenas partículas entre as lamelas da caulinita são parcialmente removidos pelo tratamento químico. 


\section{AGRADECIMENTOS}

Os autores agradecem à Mineração de Caulim Monte Pascoal Ltda. pelo fornecimento das amostras e apoio durante as etapas de campo. Ao Centro de Tecnologia Mineral (CETEM) e ao Centro Brasileiro de Pesquisas Físicas (CBPF) pela oportunidade de utilização dos seus laboratórios. Ao CNPq e a FAPERJ pelo apoio financeiro.

\section{REFERÊNCIAS BIBLIOGRÁFICAS}

1. BALAN, E.; ALLARD, T.; BOIZOT, B.; MORIN, G. and MULLER, J.P. Quantitative measurement of paramagnetic Fe3+ in kaolinite. Clays and Clay Minerals, v. 48, no 4, p. 439-445. 2000.

2. BERTOLINO, L.C. Caracterização mineralógica e tecnológica do caulim da região de Prado $B A$, visando a sua utilização na indústria de papel. Tese de Doutorado. Pontifícia Universidade Católica do Rio de Janeiro. Rio de Janeiro. 149 p. 2000.

3. BERTOLINO, L.C., ROSSI, A. M., Scorzelli, R.B., TOREM, M.L. Influence of iron on kaolin whiteness: An electron paramagnetic resonance study. Applied Clay Science, v. 49, p. 170175. 2010.

4. BIGARELLA, J.J. The Barreiras Group in Northeastern Brazil. In An. Acad. Bras. de Cien., v. 47 (Supl.), p. 365-393. 1975.

5. GRIM, R.E. Clay Mineralogy. Second ed, International Series in the Earth and Planetary Sciences. New York: McGraw-Hill Book Company. 596 p. 1968.

6. LOMBARDI, K.; GUIMARÃES, J.L.; MANGRICH, A.S.; MATTOSO, N.; ABBATE, M.; SCHREINER, W.H. and WYPYCH, F. Structural and morphological characterization of the PP-0559 kaolinite from the brazilian amazon region. J. Bras. Chem. Soc., v. 13, no 2, p. 270-275. 2002.

7. LUZ, A.B.; CAMPOS, A.R.; CARVALHO, E.A., BERTOLINO, L.C. e SCORZELLI, R.B. Argila Caulim. In Rochas \& Minerais Industriais: usos e especificações. Ed. LUZ, A.B. e LINS, F.A.F. CETEM/MCT. Rio de Janeiro. p. 255-294. 2008.

8. MONTE, M. B. M; CARVALHO, E. A.; FERREIRA, O.; CABO, S. S. Caulim CADAM. In: Usinas de Beneficiamento de Minérios do Brasil; João A. Sampaio, Adão B. Luz e Fernando Lins (Editores), p.11 - 23. 2001.

9. MEADS, R.E. and MALDEN, P.J. Electron spin resonance in natural kaolinites containing $\mathrm{Fe}^{3+}$ and other transition metal ions. Clay Minerals. v. 10, p. 313-345. 1975.

10. MURRAY, H.H. and KELLER, W. Kaolins, kaolins, and kaolins. In Kaolin Genesis and Utilization, H. Murray, W. Bundy, and C. Harvey, Editors, The Clay Minerals Society: Boulder. p. 1-24. 1993.

11. PRASAD, M.S., REID, K.J. and MURRAY, H.H. Kaolin: processing, properties and applications. Applied Clay Science. v. 6, p. 87-119. 1991.

12. SCORZELLI, R.B., BERTOLINO, L.C., LUZ, A. B., DUTTINE, M., SILVA, F.A.N.G. \& MUNYACO, P. Spectroscopy studies of kaolin from different Brazilian regions. Clay Minerals, v. 43, p. 1-7. 2008.

13. SINGH, P.K.; GANGOPADHYAY, P.K. and SHARMA, V.P. Beneficiation of China clay by chemical decolourisation and their industrial utilisation. Research and Industry. v. 36, p. 88-91. 1991. 